\title{
CYP24A1 depletion facilitates the antitumor effect of vitamin D3 on thyroid cancer cells
}

\author{
NING HU ${ }^{1}$ and $\mathrm{HAO} \mathrm{ZHANG}^{2}$ \\ ${ }^{1}$ The Second Sector of Department of Thyroid Breast Surgery, Southern Branch of Jingmen No. 1 People's Hospital; \\ ${ }^{2}$ The First Sector of Department of Thyroid Breast Surgery, Northern Branch of Jingmen No. 1 People's Hospital, \\ Jingmen, Hubei 448000, P.R. China
}

Received September 28, 2017; Accepted March 14, 2018

DOI: $10.3892 /$ etm.2018.6536

\begin{abstract}
It has been demonstrated that 25-hydroxyvitamin-D3-24-hydroxylase (CYP24A1) is a key enzyme that neutralizes vitamin D activity, which may have an anti-tumor effect. Therefore, the aim of the current study was to explore the effect of the active metabolite of vitamin D, 1,25-dihydroxyvitamin D (1,25-D3) on thyroid cancer cells following the downregulation of CYP24A1. A Cell Counting Kit-8 assay identified that CYP24A1 knockdown enhanced the anti-proliferative effects of 1,25-D3 on thyroid cancer cells. Furthermore, the results of the scratch wound and Transwell assays indicated that CYP24A1 knockdown enhanced the inhibitory effect of 1,25-D3 on cell migration. The results from reverse transcription-quantitative polymerase chain reaction and western blot analysis indicated that treatment with 1,25-D3 and CYP24A1 knockdown synergistically enhanced the expression of the epithelial-related gene E-cadherin and decreased the expression of the mesenchymal-related genes $\mathrm{N}$-cadherin and vimentin. Following CYP24A1 knockdown and treatment with 1,25-D3, the expression of matrix metalloproteinase 2 and metalloproteinase inhibitor 1 were significantly decreased and increased, respectively, compared with the group that underwent treatment with 25-D3 alone. Furthermore, protein kinase B (Akt) and $\beta$-catenin activity was significantly decreased by this synergetic effect compared with the group that underwent treatment with 1,25-D3 alone. The results of the current study suggest that CYP24A1 knockdown contributes to the anti-tumor effect of 1,25-D3 and that this effect may be due to deactivation of the Akt and $\beta$-catenin signaling pathways. Therefore, CYP24A1 knockdown and
\end{abstract}

Correspondence to: Dr Hao Zhang, The First Sector of Department of Thyroid Breast Surgery, Northern Branch of Jingmen No. 1 People's Hospital, 67 Xiangshan Avenue, Jingmen, Hubei 448000, P.R. China

E-mail: haoozhangg@163.com

Key words: 25-hydroxyvitamin-D3-24-hydroxylase, anti-tumor, 1,25-dihydroxyvitamin D, epithelial-mesenchymal transition, Akt, $\beta$-catenin
1,25-D3 treatment may be used synergistically as a novel therapeutic strategy to treat patients with thyroid cancer.

\section{Introduction}

Thyroid cancer is one of the most common endocrine tumors and its incidence is increasing globally (1). The first symptom of thyroid cancer is usually the development of thyroid nodules. More than $90 \%$ of these nodules are benign; however, malignant thyroid nodules account for $>90 \%$ of all endocrine malignancies (2). The aggressiveness of thyroid cancer increases with the reduction of cell adherence (3) Anaplastic thyroid cancer (ATC) is the most aggressive type of thyroid cancer and there are currently no effective methods of treating patients with ATC. However, understanding of the molecular pathogenesis of this cancer is increasing and a number of clinical trials have been performed to try and identify novel methods of treating this type of thyroid cancer (4).

Vitamin D is a fat-soluble prohormone that exerts important roles in calcium metabolism and homeostasis, and its active metabolite is 1,25-dihydroxyvitamin $\mathrm{D}$ (1,25-D3) (5). The primary effect of $1,25-\mathrm{D} 3$ is to regulate bone and calcium homeostasis. However, this active form of vitamin D3 also exhibits non-classical effects, including regulation of the cell cycle and various anti-tumor effects, and is therefore attracting increased attention (6-8). It has been demonstrated that 1,25-D3 is implicated in various types of cancer (9-11), including thyroid cancer, where its concentration was reduced $(12,13)$. Active vitamin $\mathrm{D}$ may serve as a ligand of the vitamin D receptor (VDR). Vitamin D signaling affects the expression of its target genes via the vitamin $\mathrm{D}$ response element (VDRE). A previous study has demonstrated the interaction of vitamin D signaling and nuclear receptor ligands in certain types of cancer (14). However, the results of clinical trials have indicated that the anti-tumor efficacy of 1,25-D3 is disappointing (15-17). Furthermore, the administration of large amounts of 1,25-D3 may induce hypercalcemia, which limits the scope of its use (18).

It remains controversial whether vitamin D exhibits an anti-cancer effect (19-22); therefore, it is important to investigate the factors that may affect the anti-cancer effect of vitamin D in cancer cells. The metabolism of vitamin D is highly complex and a series of enzymes are involved in 
its synthesis, activation and inactivation (23). The enzyme 25-hydroxyvitamin-D3-24-hydroxylase (CYP24A1), is responsible for neutralizing active 1,25 -D3 and is an important component of the mitochondrial enzyme cytochrome P450 (24). This 1,25-D3-inactivating enzyme is critical in determining the antitumor activity of 1,25-D3. It has been demonstrated that high expression of CYP24A1 facilitates carcinogenesis in colorectal cancer (25). Thus, the aim of the current study was to identify whether CYP24A1 affects the anti-tumor effect of 1,25-D3 in thyroid cancer.

The protein kinase B (Akt) signaling pathway enhances cell survival and tumorigenesis (26-28). Abnormal activation of Akt may be associated with the progression of thyroid tumors $(29,30)$. In addition, $\beta$-catenin, another important signaling molecule in cells, has attracted extensive attention due to its critical role in differentiation and regulation of patterning (31). The activity of $\beta$-catenin in tumors is enhanced by various mutations (32-34). Furthermore, the alteration of $\beta$-catenin activity has been identified in the majority of aggressive thyroid tumors (35). Based on these results, the current study sought to explore the effect of 1,25-D3 on the proliferation and metastasis of thyroid cancer cells following the inhibition of CYP24A1 and to determine its molecular mechanisms of action.

\section{Materials and methods}

Cell culture. The anaplastic thyroid cancer cell line KAT-18 was purchased from the American Type Culture Collection (Manassas, VA, USA). Cells were kept in RPMI 1640 medium (Thermo Fisher Scientific, Inc., Waltham, MA) with 10\% fetal bovine serum (FBS Gibico; Thermo Fisher Scientific, Inc.) at $37^{\circ} \mathrm{C}$ in a humidified incubator containing $5 \% \mathrm{CO}_{2}$.

Cell transfection. To knockdown CYP24A1 expression, cells were seeded in 24 -well plates at a density of $2 \times 10^{5} /$ well. When cells reached $50-60 \%$ confluence, they were cultured in serum-free medium overnight. Cells were then transfected with $100 \mathrm{nM}$ human CYP24A1siRNA (cat. no. sc-44652; Santa Cruz Biotechnology, Inc., Dallas, TX, USA) or $100 \mathrm{nM}$ scramble control siRNA (cat. no. sc-37007; Santa Cruz Biotechnology, Inc.) using X-tremeGENE ${ }^{\text {TM }}$ siRNA transfection reagent (Roche Diagnostics, Basel, Switzerland) following the manufacturer's protocol. Following $36 \mathrm{~h}$ incubation, cells were treated with or without $100 \mathrm{nM} 1,25-\mathrm{D} 3$ (Sigma-Aldrich; Merck KGaA, Darmstadt, Germany) for $4 \mathrm{~h}$; this concentration of 1,25-D3 was selected according to the results of previous studies $(36,37)$. Cells in all relevant groups received the same concentration of 1,25-D3 (100 nM). All subsequent experiments were independently performed $\geq 3$ times.

Cell grouping. Cells were divided into different groups as follows: A control group (untreated cells); cells treated with $100 \mathrm{nM}$ 1,25-D3 for $4 \mathrm{~h}$ (VD3); cells transfected with scramble control siRNA and treated with $100 \mathrm{nM}$ 1,25-D3 (siscr+VD3); cells transfected with CYP24A1 siRNA and treated with $100 \mathrm{nM}$ 1,25-D3 (siCYP+VD3); cells transfected with scramble control siRNA (siscr) and cells transfected with CYP24A1siRNA (siCYP).
Cell proliferation assay. Cells were seeded at $1 \times 10^{5}$ cell/well in 24-well plates. A Cell Counting Kit 8 (CCK-8) assay was used to measure the proliferation of cells in each group. The CCK-8 solution from the Cell Counting Kit (Beijing Solarbio Science \& Technology, Co., Ltd., Beijing, China) was added to each well $(10 \mu \mathrm{l} / \mathrm{well})$. Cells were then maintained at $37^{\circ} \mathrm{C}$ for $4 \mathrm{~h}$. The absorbance of the reaction regent was determined at $450 \mathrm{~nm}$ using a microplate reader (Bio-Rad Laboratories, Inc., Hercules, CA, USA).

Cell migration assay. Cells $(2 \mathrm{ml})$ at a density of $1 \times 10^{5} / \mathrm{ml}$ were placed on the upper cell culture chambers containing Transwell inserts (Corning Incorporated, Corning, NY, USA) and maintained in medium containing $0.2 \%$ FBS. The lower chamber was supplemented with the medium containing $15 \%$ FBS. The chambers were incubated for $24 \mathrm{~h}$ and then cells retained on the upper chamber were removed. Cells that migrated to the lower chamber were fixed with $4 \%$ paraformaldehyde at room temperature for $20 \mathrm{~min}$. Cells were then stained with $0.1 \%$ crystal violet at room temperature for $20 \mathrm{~min}$ and observed using an optical microscope at a magnification of x 200 .

Scratch wound assay. Following transfection, cells were cultured in complete medium for a further $12 \mathrm{~h}$. A sterile pipette tip was used to scratch the wells and cells were then incubated in serum-free solution following washing with PBS. The distance of the scratch was measured at 0 and $24 \mathrm{~h}$ following incubation using an inverted microscope at a magnification of $\mathrm{x} 100$.

Reverse transcription-quantitative polymerase chain reaction $(R T-q P C R)$. Total RNA was isolated using TRIzol $^{\circledR}$ regent (Invitrogen; Thermo Fisher Scientific, Inc.). The purification and concentration of RNA was measured at 260/280 nm using an ultra-micro spectrophotometer (NanoDrop Technologies; Thermo Fisher Scientific, Inc.). The integrity of RNA was detected using $1 \%$ agarose gel electrophoresis. A total of $1 \mu \mathrm{g}$ RNA was reverse transcribed using M-MLV reverse transcriptase (Promega Corporation, Madison, WI, USA), ribonuclease inhibitor and oligo(dT18) (Takara Bio, Inc., Otsu, Japan), $5 \mathrm{X}$ buffer (Takara Bio, Inc.) and dNTP (Takara Bio, Inc.) in $20 \mu \mathrm{l}$ volumes. The temperature protocol used for reverse transcription was: $25^{\circ} \mathrm{C}$ for $10 \mathrm{~min} ; 42^{\circ} \mathrm{C}$ for $50 \mathrm{~min}$; and $70^{\circ} \mathrm{C}$ for $15 \mathrm{~min}$. A SYBR ${ }^{\circledR}$ Premix Taq ${ }^{\mathrm{TM}}$ II kit (Takara Bio, Inc.) was used to amplify cDNA on a Mx3000 platform (Agilent Technologies, Inc., Santa Clara, CA, USA) following the manufacturer's protocol. The thermocycling conditions were as follows: $95^{\circ} \mathrm{C}$ for $4 \mathrm{~min} ; 35$ cycles of $95^{\circ} \mathrm{C}$ for 30 sex; $60^{\circ} \mathrm{C}$ for $30 \mathrm{sec}$; and $72^{\circ} \mathrm{C}$ for $10 \mathrm{~min}$. The relative expression level was calculated using the $2^{-\Delta \Delta \mathrm{Cq}}$ method (38). The primers used were as follows: E-cadherin, forward, 5'-TCA CATCCTACACTGCCCAG-3' and reverse, 5'-AGTGTCCCT GTTCCAGTAGC-3'; N-cadherin forward, 5'-ATATTTCCA TCCTGCGCGTG-3' and reverse, 5'-GTTTGGCCTGGC GTTCTTTA-3'; vimentin, forward, 5'-GAGAGGAAGCCG AAAACACC-3' and reverse, 5'-TTCCTGAATCTGAGC CTGCA-3'; matrix metalloproteinase (MMP) 2, forward, 5'-ACCACAGCCAACTACGATGA-3' and reverse, 5'-GCT CCTGAATGCCCTTGATG-3'; MMP9, forward, 5'-GCG TCTTCCCCTTCACTTTC-3' and reverse, 5'-ATAGGGTAC 
ATGAGCGCCTC-3'; metalloproteinase inhibitor (TIMP) 1, forward, 5'-ACTACCTGCAGTTTTGTGGC-3' and reverse, 5'-CTGGAAGCCCTTTTCAGAGC-3'; CYP24A1 forward, 5'-CCGTAATCCCCAAGTGCAAC-3' and reverse, 5'-CCC AGAACTGTTGCCTTGTC-3'; VDR, forward, 5'-ACTCCA CCACCCAAAAGTCA-3' and reverse, 5'-GCATTCCCCAAA CTCAAGCA-3'; $\beta$-actin, forward, 5'-CTCCATCCTGGCCTC GCTGT-3' and reverse, 5'-GCTGTCACCTTCACCGTTCC-3'.

Western blot analysis. Radioimmunoprecipitation assay lysis buffer containing protease inhibitors (Roche Diagnostics, Basel, Switzerland) was used to extract the total protein. Protein concentration was determined using Bio-Rad protein assay kits (Bio-rad Laboratories, Inc.). Proteins (20 $\mu \mathrm{g} /$ lane) were resolved using 8-10\% SDS-PAGE and transferred onto a PVDF membrane (EMD Millipore, Billerica, MA, USA). Subsequently, membranes were blocked using a blocking buffer ( $20 \mathrm{mM}$, Tris-base, $150 \mathrm{mM} \mathrm{NaCl})$ containing $0.1 \%$ Tween-20 and non-fat milk for $2 \mathrm{~h}$ at room temperature. Following washing with PBS, the membrane was incubated with primary antibodies against CYP24A1 (cat. no. sc-365700; 1:700; Santa Cruz Biotechnology, Inc.), VDR (cat. no. sc-13133; 1:500; Santa Cruz Biotechnology, Inc.), Akt1/2 (cat. no. sc81434; 1:1,000; Santa Cruz Biotechnology, Inc.), phosphorylated (p)-Akt (cat. no. ab81283; 1:5,000; Abcam, Cambridge, UK), $\beta$-catenin (cat. no. ab32572; 1:5,000; Abcam), N-cadherin (cat. no. C2542; 1:100; Sigma-Aldrich; Merck KGaA), E-cadherin (cat. no. SAB4503751; 1:1,000, Sigma-Aldrich; Merck KGaA), vimentin (cat. no. V5255; 1:500; Sigma-Aldrich; Merck KGaA), MMP-2 (cat. no. 40994; 1:1,000; Cell signaling technology, Inc., Danvers, MA, USA), MMP-9 (cat. no. 13667; 1:1,000; Cell signaling technology, Inc.), TIMP1 (cat. no. 8946; 1:1,000; Cell signaling technology, Inc.) and $\beta$-actin (cat. no. 3700; 1:1,000; Cell signaling technology, Inc.) overnight at $4^{\circ} \mathrm{C}$. Subsequently, the membrane was incubated with horseradish peroxidase conjugated secondary antibodies (cat. no. ab6728; 1:2,000; Abcam) for $1 \mathrm{~h}$ at room temperature. Immunoblots were visualized using enhanced chemiluminescence (Beyotime Institute of Biotechnology, Haimen, China). ImageJ software version 1.46 (National Institutes of Health, Bethesda, MD, USA) was used to quantify protein expression.

Statistical analysis. Data are presented as the mean \pm standard deviation. One-way analysis of variance followed by a Turkey's post-hoc test was performed to compare differences between groups. $\mathrm{P}<0.05$ was considered to indicate a statistically significant difference. GraphPad Prism 6.0 software (GraphPad Software Inc., La Jolla, CA, USA) was used to perform data analysis.

\section{Results}

The effect of CYP24A1 knockdown and 1,25-D3 treatment on cell proliferation. The association between enhanced CYP24A1 activity and tumorigenesis has been previously reported (8). Following transfection with CYP24A1 siRNA, CYP24A1 expression was significantly downregulated (Fig. 1A-C), meaning that the combined effect of CYP24A1 and 1,25-D3 on thyroid cancer cells could be explored effectively. The results of the CCK- 8 assay indicated that the proliferation of thyroid cancer cells was significantly inhibited in the VD3 group and the siCYP group, compared with the control (Fig. 1D). Furthermore, cell proliferation was significantly inhibited in the siCYP+VD3 group compared with the VD3 and siCYP groups (Fig. 1D). These results suggest that CYP24A1 knockdown and 1,25-D3 treatment synergistically suppress cell proliferation.

The effect of CYP24A! knockdown and 1,25-D3 treatment on the expression of CYP24A1 and VDR. Impaired 1,25-D3-VDR signaling serves an important role in the progression of thyroid cancer (39). It has also been demonstrated that the expression of CYP24A1 is increased by $1,25-\mathrm{D} 3(8,40)$. Thus, levels of CYP24A1 and VDR in the presence of 1,25-D3 were measured. The results revealed that 1,25-D3 treatment increased CYP24A1 mRNA (Fig. 2A) and protein (Fig. 2B and C) expression whereas CYP24A1 expression was significantly decreased following treatment with siCYP. By contrast, VDR expression did not change significantly following treatment with 1,25-D3 or transfection with siCYP (Fig. 2).

The effect of CYP24A1 knockdown and 1,25-D3 treatment on cell migration. The migration of thyroid cancer cells was measured using Transwell and scratch assays. The number of migrating cells significantly decreased following treatment with 1,25-D3 or transfection with CYP24A1siRNA, compared with untreated cells (Fig. 3). Furthermore, the number of migrating cells was significantly lower in the group of cells that underwent transfection with CYP24A1siRNA and treatment with 1,25-D3, compared with the group that underwent treatment with 1,25-D3 alone (Fig. 3B).

The results of the scratch wound assay demonstrated that the relative migration distance was $0.5 \pm 0.06 \mathrm{~mm}$ in the control group, $0.78 \pm 0.11 \mathrm{~mm}$ in the VD3 group, $0.74 \pm 0.09 \mathrm{~mm}$ in the siscr+VD3 group, $0.98 \pm 0.13 \mathrm{~mm}$ in the siCYP+VD3 group, $0.47 \pm 0.06 \mathrm{~mm}$ in the siscr group and $0.57 \pm 0.08 \mathrm{~mm}$ in the siCYP group (Fig. 4). Significant differences were observed in the relative wound width between the VD3, Siscr+VD3, siCYP+VD3 groups compared with the control group. Furthermore, the migration distance was significantly higher in the siCYP+VD3 compared with the VD3 group.

The effect of CYP24A1 knockdown and 1,25-D3 treatment on the expression of epithelial-mesenchymal transition (EMT)-associated genes. The EMT is considered to be responsible for tumor cell migration and invasion, and production of the extracellular cell matrix (ECM) during tumor progression $(41,42)$. E-cadherin is highly expressed in epithelial cells whereas $\mathrm{N}$-cadherin and vimentin are abundant in mesenchymal cells (43). The results of the western blotting revealed that the expression of E-cadherin was significantly increased in cells treated with 1,25-D3 or CYP24A1siRNA (Fig. 5A and B). Furthermore, treatment with 1,25-D3 and CYP24A1siRNA synergistically enhanced the mRNA expression of this epithelial related gene (Fig. 5C). By contrast, the expression of $\mathrm{N}$-cadherin and Vimentin significantly decreased following treatment with $1,25-\mathrm{D} 3$ or CYP24A1, with the greatest decrease in the group that underwent treatment with 1,25-D3 and CYP24A1. 
A

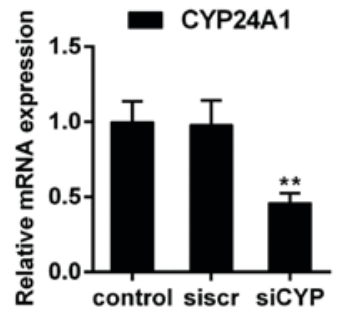

B

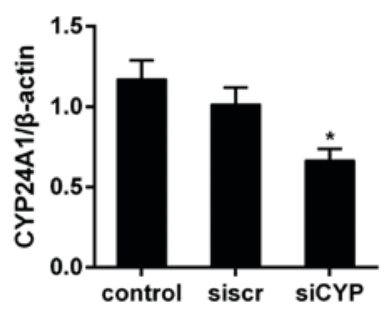

C

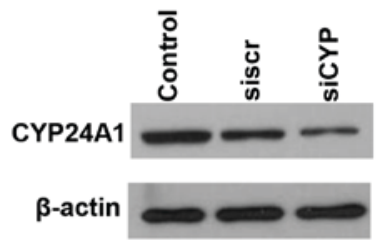

D

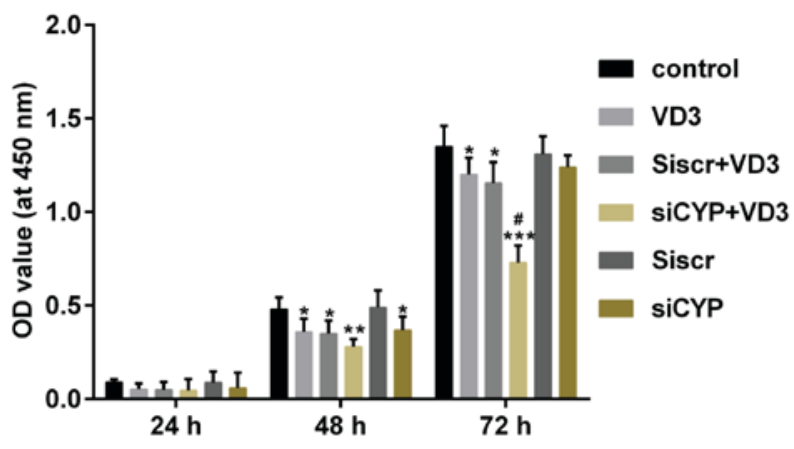

Figure 1. (A) Quantitative analysis of CYP24A1 mRNA expression following transfection with siRNA. **P<0.01 vs. control. (B) Determination of CYP24A1 protein expression following transfection with siRNA. "P $<0.05$ vs. control. (C) Western blot analysis of CYP24A1 expression following transfection with siRNA. $\beta$-actin was used as a sample loading control. (D) Determination of cell proliferation using a Cell Counting Kit- 8 . ${ }^{*} \mathrm{P}<0.05$, ${ }^{* *} \mathrm{P}<0.01$ and ${ }^{* * * *} \mathrm{P}<0.001$ vs. control; " $\mathrm{P}<0.05$ vs. VD3 group. Control, untreated cells; VD3, cells treated with 1,25-D3 for $4 \mathrm{~h}$; siscr+VD3, cells transfected with scramble control siRNA and treated with 1,25-D3; siCYP+VD3, cells transfected with CYP24A1 siRNA and treated with 1,25-D3; siscr, cells transfected with scramble control siRNA; siCYP, cells transfected with CYP24A1siRNA; siRNA, small interfering RNA; CYP24D1, 25-hydroxyvitamin-D3-24-hydroxylase; 1,25-D3, 1,25-dihydroxyvitamin D.

A

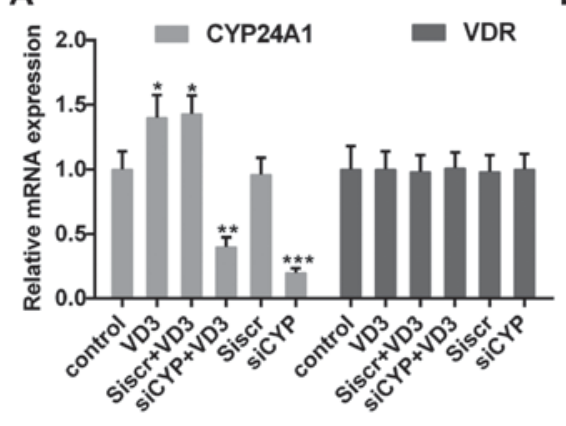

B

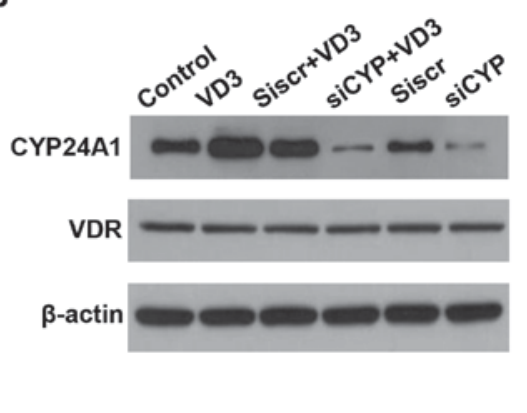

C

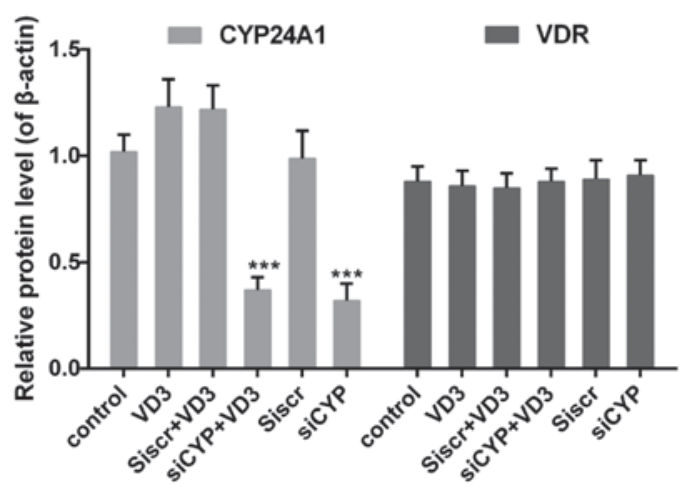

Figure 2. (A) Quantitative analysis of CYP24A1 and VDR mRNA expression. ${ }^{*} \mathrm{P}<0.05,{ }^{* *} \mathrm{P}<0.01$ and ${ }^{* * * *} \mathrm{P}<0.001$ vs. control. (B) Western blotting and (C) quantification of CYP24A1 and VDR protein expression. $\beta$-actin was used as the sample loading control. ${ }^{* * *} \mathrm{P}<0.001$ vs. control. Control, untreated cells; VD3, cells treated with 1,25-D3 for $4 \mathrm{~h}$; siscr+VD3, cells transfected with scramble control siRNA and treated with 1,25-D3; siCYP+VD3, cells transfected with CYP24A1 siRNA and treated with 1,25-D3; siscr, cells transfected with scramble control siRNA; siCYP, cells transfected with CYP24A1siRNA; siRNA, small interfering RNA; CYP24D1, 25-hydroxyvitamin-D3-24-hydroxylase; VDR, vitamin D receptor; 1,25-D3, 1,25-dihydroxyvitamin D. 
A
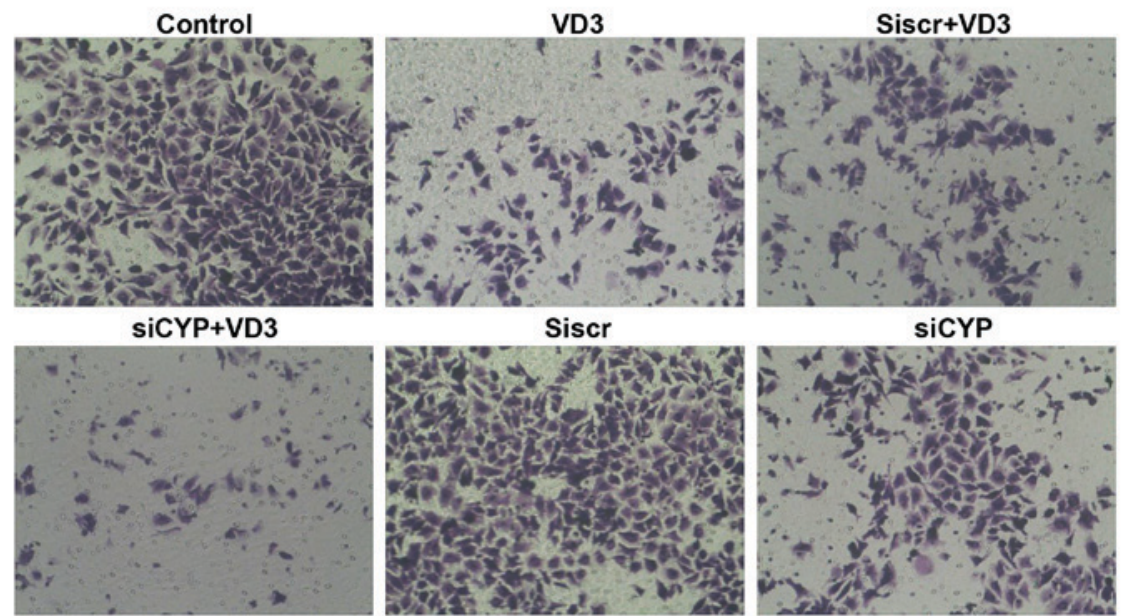

B

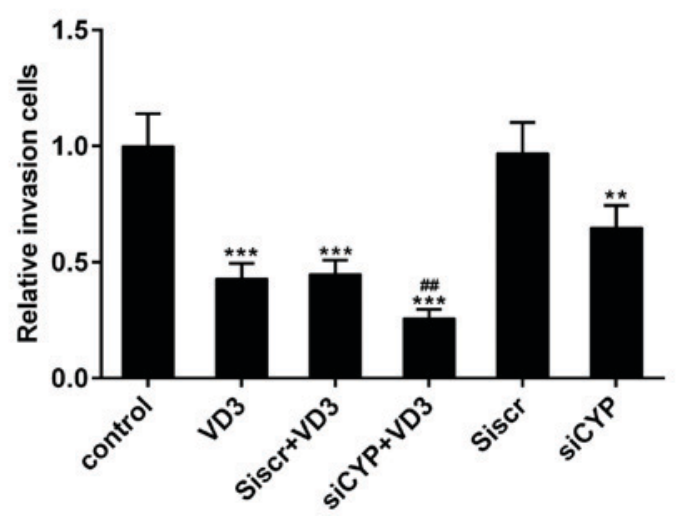

Figure 3. (A) Measurement of cell migration using a Transwell assay. Magnification, $\mathrm{x} 200$. (B) Relative numbers of migrating cells. ${ }^{* *} \mathrm{P}<0.01$ and ${ }^{* * *} \mathrm{P}<0.001$ vs. control; "\#" $\mathrm{P}<0.01$ vs. VD3 group. Control, untreated cells; VD3, cells treated with 1,25-D3 for $4 \mathrm{~h}$; siscr+VD3, cells transfected with scramble control siRNA and treated with 1,25-D3; siCYP+VD3, cells transfected with CYP24A1 siRNA and treated with 1,25-D3; siscr, cells transfected with scramble control siRNA; siCYP, cells transfected with CYP24A1siRNA; siRNA, small interfering RNA; CYP24D1, 25-hydroxyvitamin-D3-24-hydroxylase; 1,25-D3, 1,25-dihydroxyvitamin D.

The effect of CYP24A1 knockdown and 1,25-D3 treatment on the expression of MMPs. MMPs serve a critical role in the migration and metastasis of tumor cells, which is essential for inducing degradation of the ECM (44). The expression of MMP-2 mRNA and protein was significantly decreased in the siCYP+VD3 group compared with VD3 and control groups (Fig. 6). By contrast, the expression of MMP-9 mRNA and protein was unaffected in all treatment groups; there was a slight decrease in MMP-9 expression in the siCYP+VD3 group, although this was not significant. The mRNA and protein expression of TIMP1, which inhibits the expression of MMPs (45), was increased following treatment with 1,25-D3 or CYP24A1siRNA. This increase was significantly greater in the siCYP+VD3 group compared with the VD3 group.

The effect of CYP24A1 knockdown and 1,25-D3 treatment on the activity of AKT and $\beta$-catenin. AKT activation and $\beta$-catenin inhibition are correlated with the pathogenesis of thyroid cancer $(31,46)$. As presented in Fig. 7A and B, the phosphorylation of AKT was significantly decreased in cells following treatment with 1,25-D3 or CYP24A1siRNA. Furthermore, the expression of $\mathrm{p}$-AKT was significantly decreased in the siCYP+VD3 group compared with the VD3 group. $\beta$-catenin activity was also significantly decreased in the siCYP+VD3 groups compared with the control and VD3 groups.

\section{Discussion}

To determine the influence of the enzyme CYP24A1 on the anti-tumor effect of vitamin D3, its expression was decreased using specific siRNA. The proliferation of thyroid cancer cells was assessed using a CCK- 8 assay and it was demonstrated that thyroid cell proliferation was significantly inhibited following treatment with 1,25-D3 or CYP24A1 knockdown. Furthermore, CYP24A1 knockdown significantly enhanced the anti-proliferative effects of 1,25-D3 $72 \mathrm{~h}$ after treatment, compared with cells that were treated with 1,25-D3 alone. It has been reported that the susceptibility of cancer cells to vitamin D3 gradually decreases during tumor progression (15); nevertheless, its mechanisms of action remain unclear. In the present study, the effect of 1,25-D3 on the expression of CYP24A1 and VDR, which are important factors that affect the anti-tumor effect of vitamin D3, was assessed. It was demonstrated that 1,25-D3 treatment increased CYP24A1 expression but had no influence on VDR expression. The elevated expression of 
A
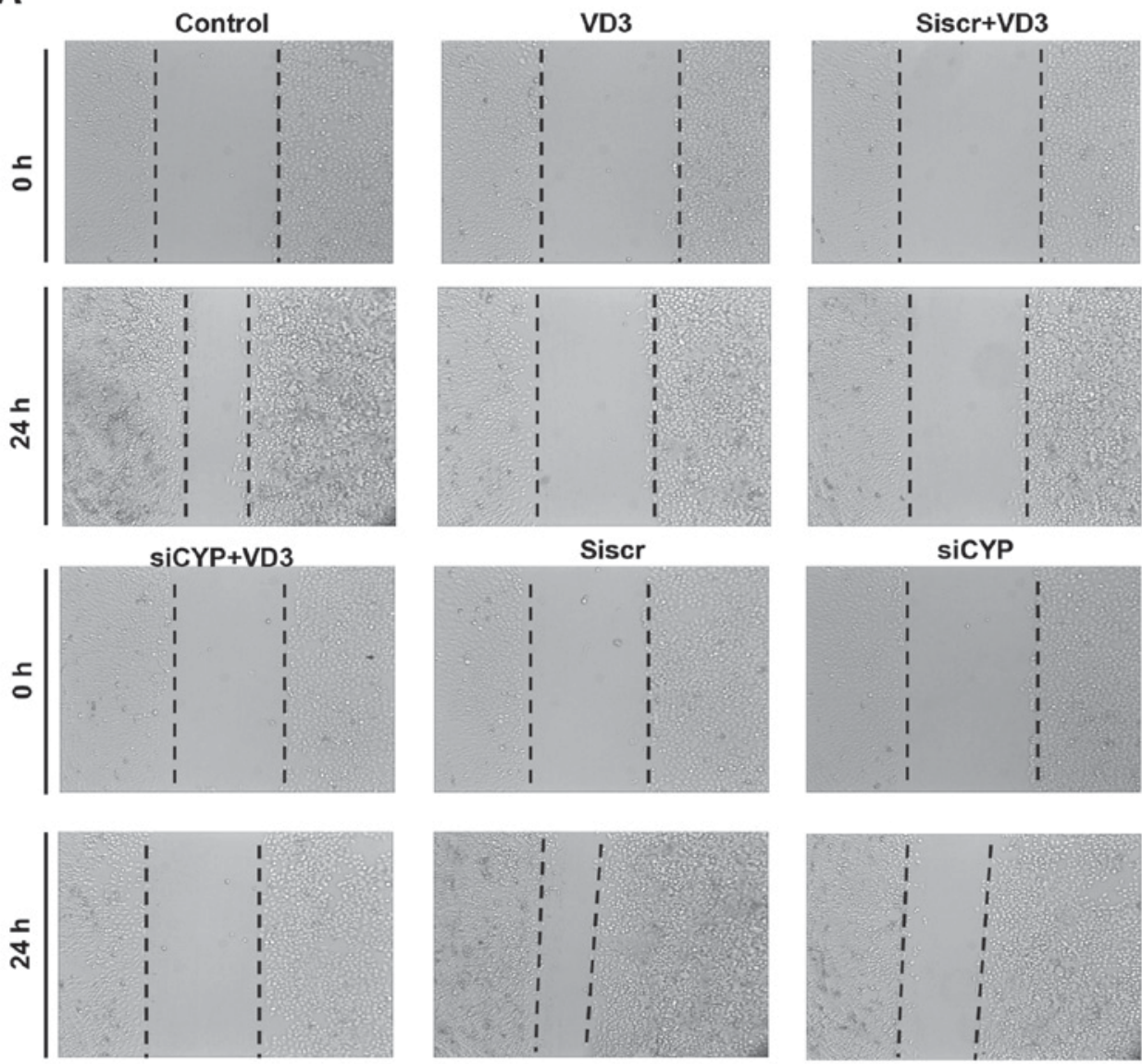

B

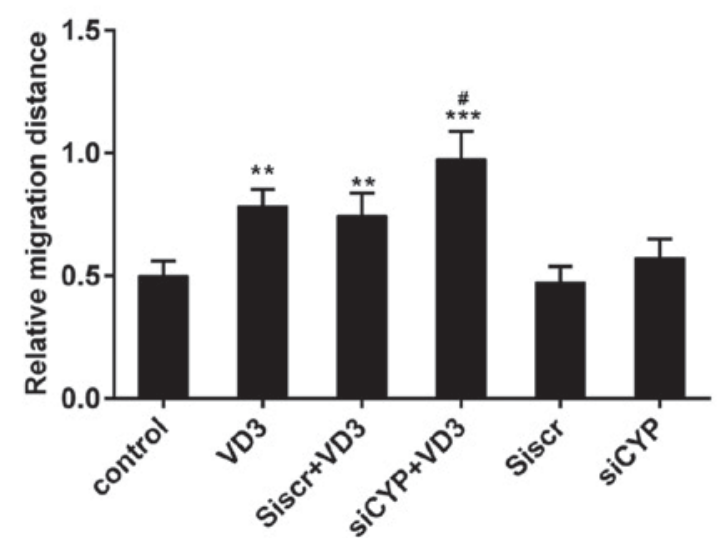

Figure 4. (A) Assessment of tumor cell migration using a scratch assay. Magnification, $\mathrm{x} 100$. (B) Relative wound width of tumor cells in each group. ${ }^{* *} \mathrm{P}<0.01$ and ${ }^{* * *} \mathrm{P}<0.001$ vs. control; ${ }^{\#} \mathrm{P}<0.05$ vs. VD3 group. Control, untreated cells; VD3, cells treated with 1,25-D3 for 4 h; siscr+VD3, cells transfected with scramble control siRNA and treated with 1,25-D3; siCYP+VD3, cells transfected with CYP24A1 siRNA and treated with 1,25-D3; siscr, cells transfected with scramble control siRNA; siCYP, cells transfected with CYP24A1 siRNA; siRNA, small interfering RNA; CYP24D1, 25-hydroxyvitamin-D3-24-hydroxylase; 1,25-D3, 1,25-dihydroxyvitamin D.

CYP24A1 following 1,25-D3 treatment was in line with a previous study (47). This may be a self-defense mechanism of cancer cells and may partly explain why the anti-tumor effect of 1,25-D3 is weakened following treatment.

Tumor metastasis is usually accompanied by tumor cell invasion and migration to other tissues, and the initiation of the EMT, which may lead to the loss of the epithelial phenotype and gain of fibroblast-like mesenchymal morphology (48). The results of a Transwell assay assessing cell migration indicated that 1,25-D3 treatment and CYP24A1 knockdown significantly inhibited the migration of thyroid cancer cells. Cell migration was significantly decreased in the group that underwent CYP24A1 knockdown and treatment with 1,25-D3 compared with the groups that underwent 1,25-D3 treatment alone.

In addition, the results of a scratch wound assay indicated that the migratory ability of thyroid cancer cells was decreased following treatment with 1,25-D3, as well as following CYP24A1 knockdown. Likewise, CYP24A1 knockdown enhanced the inhibitory effect of 1,25-D3 on cell migration. The decrease in the expression of the epithelial-related 
A

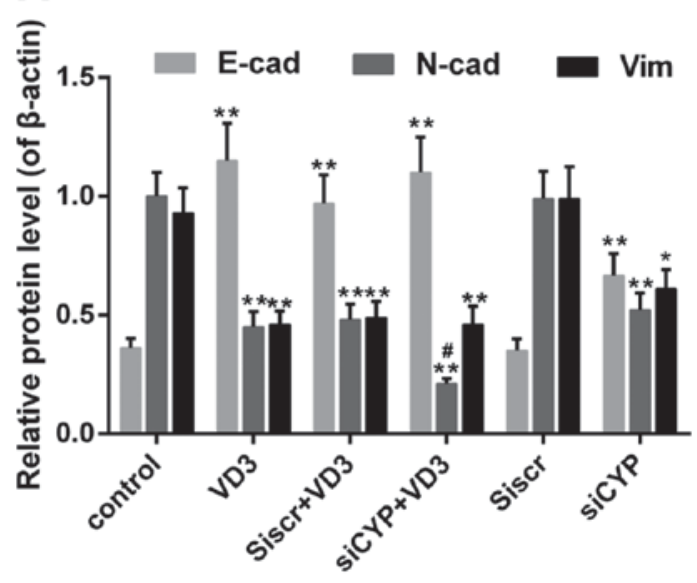

B

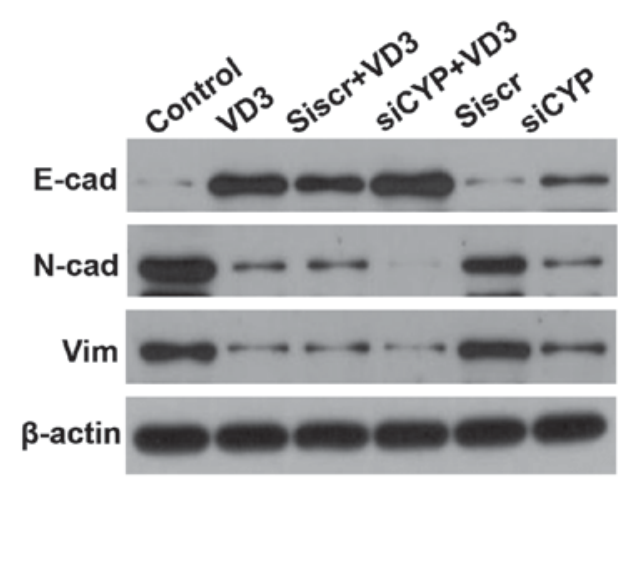

C

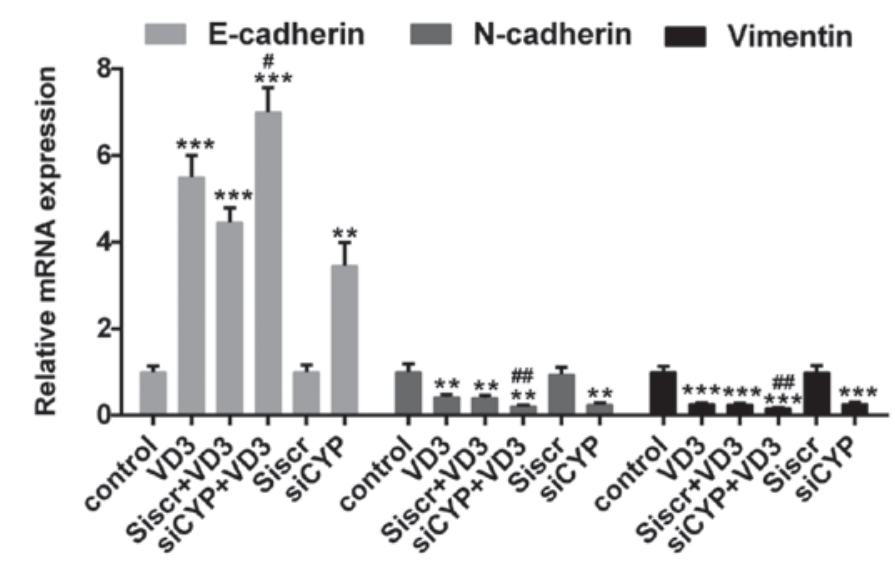

Figure 5. (A and B) Western blot analysis measuring E-cadherin, N-cadherin and vimentin expression. $\beta$-actin was used as sample loading control. (C) The expression of E-cadherin, $\mathrm{N}$-cadherin and vimentin mRNA. ${ }^{*} \mathrm{P}<0.05,{ }^{* *} \mathrm{P}<0.01$ and ${ }^{* * *} \mathrm{P}<0.001$ vs. control; ${ }^{*} \mathrm{P}<0.05$ and ${ }^{\# *} \mathrm{P}<0.01$ vs. VD3 group. Control, untreated cells; VD3, cells treated with 1,25-D3 for $4 \mathrm{~h}$; siscr+VD3, cells transfected with scramble control siRNA and treated with 1,25-D3; siCYP+VD3, cells transfected with CYP24A1 siRNA and treated with 1,25-D3; siscr, cells transfected with scramble control siRNA; siCYP, cells transfected with CYP24A1siRNA; siRNA, small interfering RNA; CYP24D1, 25-hydroxyvitamin-D3-24-hydroxylase; 1,25-D3, 1,25-dihydroxyvitamin D.

protein E-cadherin and the increase in the expression of the mesenchymal-related proteins $\mathrm{N}$-cadherin and vimentin were reversed by $1,25-\mathrm{D} 3$ treatment and also by CYP24A1 knockdown. This effect was more pronounced in the group that underwent 1,25-D3 treatment and CYP24A1 knockdown compared with the group that underwent 1,25-D3 treatment alone, suggesting that a decrease in CYP24A1 expression inhibits the EMT.

MMPs are key enzymes that affect degradation of the ECM, an important step in the progression of the EMT (49). The results demonstrated that the expression of MMP-2 expression decreased and TIMP1 expression increased in the three treatment groups (VD3, siCYP and siCYP+VD3); MMP-9 expression was similar among all groups. Taken together, these results suggest that CYP24A1 knockdown facilitates the anti-tumor effect of 1,25 -D3 by inhibiting the migration of thyroid cancer cells and the EMT.

A deep understanding of the underlying mechanisms is required to facilitate the development of precise targets during the intervention and treatment of thyroid cancer. Previous studies have identified the role of Akt and $\beta$-catenin in multiple biological events $(31,46,50)$. In the present study, it was noted that the treatment with 1,25-D3 suppressed Akt and $\beta$-catenin activity and that this effect was most prominent when 1,25-D3 treatment was initiated following CYP24A1 knockdown. These results are in line with those of a previous study, which also claimed that the deactivation of $\beta$-catenin could induce the expression of E-cadherin (51). However, in the current study, the association between $\beta$-catenin and EMT markers remained obscure; further studies are required to validate this. Furthermore, it has been reported that activation of the phosphoinositide 3-kinase/Akt pathway can phosphorylate $\beta$-catenin at a specific site, leading to its accumulation and stabilization in the nucleus (52). However, it remains unclear whether Akt affects the activity of $\beta$-catenin. It has been reported that $\beta$-catenin may be at the convergence of multiple signaling pathways in thyroid cancer (31). Therefore, a signaling pathway that was not assessed in the current study may participate in the regulation of thyroid cancer. It is important to undertake in-depth studies to determine the definite mechanisms of action of 1,25-D3 and CYP24A1. If the synergetic effect of 1,25-D3 and CYP24A1 is confirmed in vivo, it would be a big step forward in developing a novel therapeutic strategy to treat thyroid cancer. 
A

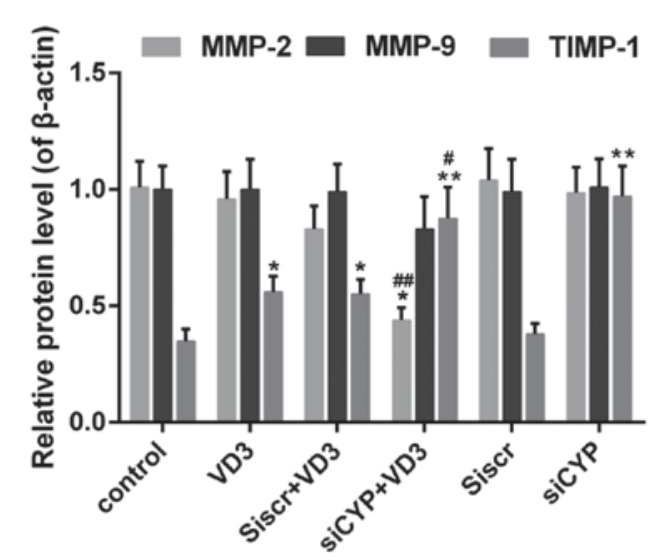

B

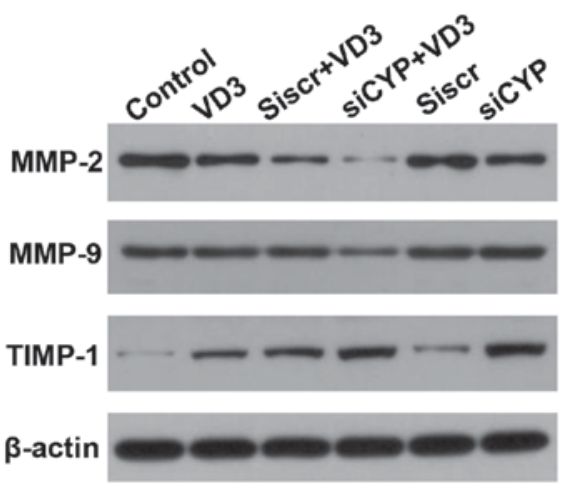

C

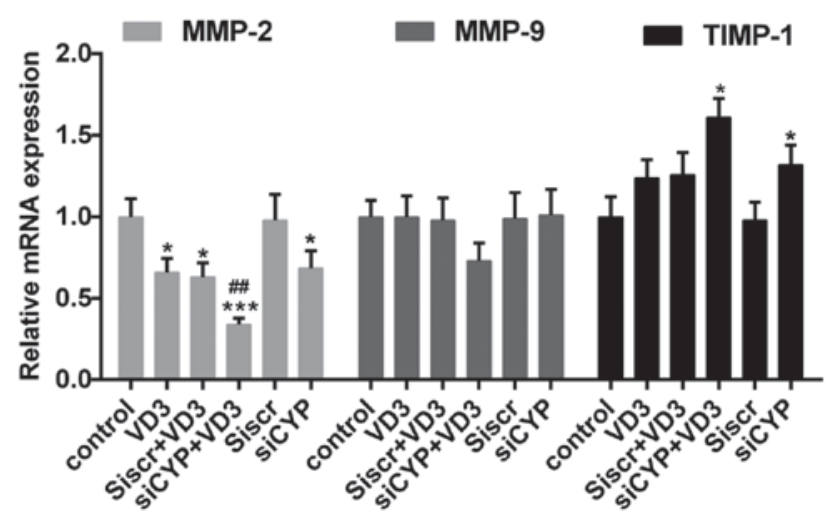

Figure 6. (A and B) Western blot analysis measuring MMP-2, MMP-9 and TIMP1 expression. $\beta$-actin was used as sample loading control. (C) The expression of MMP-2, MMP-9 and TIMP1 mRNA. ${ }^{*} \mathrm{P}<0.05,{ }^{* *} \mathrm{P}<0.01$ and ${ }^{* * *} \mathrm{P}<0.001$ vs. control; ${ }^{*} \mathrm{P}<0.05$ and ${ }^{\# \#} \mathrm{P}<0.01$ vs. VD3 group. Control, untreated cells; VD3, cells treated with $10 \mathrm{nM}$ 1,25-D3 for $4 \mathrm{~h}$; siscr+VD3, cells transfected with scramble control siRNA and treated with 1,25-D3; siCYP+VD3, cells transfected with CYP24A1 siRNA and treated with 1,25-D3; siscr, cells transfected with scramble control siRNA; siCYP, cells transfected with CYP24A1siRNA; siRNA, small interfering RNA; CYP24D1, 25-hydroxyvitamin-D3-24-hydroxylase; 1,25-D3, 1,25-dihydroxyvitamin D; MMP, matrix metalloproteinase; TIMP, metalloproteinase inhibitor.

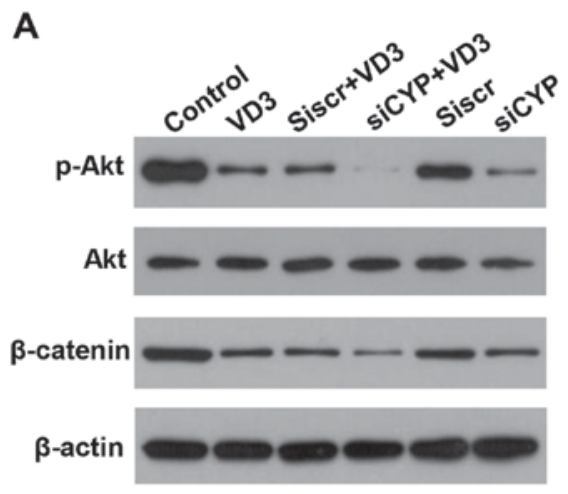

B

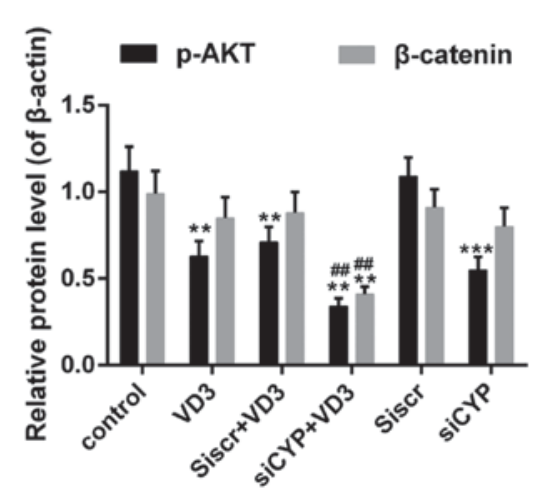

Figure 7. (A and B) Western blot analysis of $\mathrm{p}$-Akt and $\beta$-catenin expression. $\beta$-actin was used as sample loading control. ${ }^{* *} \mathrm{P}<0.01$ and ${ }^{* * * *} \mathrm{P}<0.001 \mathrm{vs}$. control; ${ }^{\# \prime} \mathrm{P}<0.01$ vs. VD3 group. Control, untreated cells; VD3, cells treated with $10 \mathrm{nM}$ 1,25-D3 for $4 \mathrm{~h}$; siscr+VD3, cells transfected with scramble control siRNA and treated with 1,25-D3; siCYP+VD3, cells transfected with CYP24A1 siRNA and treated with 1,25-D3; siscr, cells transfected with scramble control siRNA; siCYP, cells transfected with CYP24A1 siRNA; siRNA, small interfering RNA; CYP24D1, 25-hydroxyvitamin-D3-24-hydroxylase; 1,25-D3, 1,25-dihydroxyvitamin D; p-phosphorylated; Akt, protein kinase B.

In conclusion, the results of the present study demonstrated that the downregulation of CYP24A1 facilitated the anti-tumor effect of vitamin D3. This anti-tumor effect primarily occurred via the suppression of tumor cell proliferation and migration. Furthermore, the expression of the EMT-related genes E-cadherin, N-cadherin and Vimentin, and MMP-2 and 
TIMP1 were regulated following treatment with 1,25-D3 and CYRP24A1 knockdown. This effect may be induced via the deactivation of Akt and $\beta$-catenin.

\section{Acknowledgements}

Not applicable.

\section{Funding}

No funding was received.

\section{Availability of data and materials}

The datasets used and/or analyzed during the current study are available from the corresponding author on reasonable request.

\section{Authors' contributions}

$\mathrm{NH}$ performed the experiments and data analysis and contributed significantly to the preparation of the manuscript. HZ contributed to the experimental design.

\section{Ethics approval and consent to participate}

Not applicable.

\section{Consent for publication}

Not applicable.

\section{Competing interests}

The authors declare that they have no competing interests.

\section{References}

1. Davies L and Welch HG: Increasing incidence of thyroid cancer in the United States, 1973-2002. JAMA 295: 2164-2167, 2006.

2. Sherma SI: Thyroid carcinoma. Lancet 361: 501-511, 2003.

3. Dobrinja C: Papillary thyroid cancer gender disparity. 2014.

4. Kapiteijn E, Schneider TC, Morreau H, Gelderblom H, Nortier JW and Smit JW: New treatment modalities in advanced thyroid cancer. Ann Oncol 23: 10-18, 2012.

5. Boot AC: Vitamin-D deficiency. Ned Tijdschr Geneeskd 150: 1315-1316, 2006 (In Dutch).

6. Deeb KK, Trump DL and Johnson CS: Vitamin D signalling pathways in cancer: Potential for anticancer therapeutics. Nat Rev Cancer 7: 684-700, 2007.

7. Clinckspoor I, Verlinden L, Mathieu C, Bouillon R, Verstuyf A and Decallonne B: Vitamin D in thyroid tumorigenesis and development. Prog Histochem Cytochem 48: 65-98, 2013.

8. Balla B, Tobias B, Kósa JP, Podani J, Horváth P, Nagy Z, Horanyi J, Jaray B, Szekely E, Krenács L, et al: Vitamin D-neutralizing CYP24A1 expression, oncogenic mutation states and histological findings of human papillary thyroid cancer. J Endocrinol Invest 38: 313-321, 2015.

9. Hershberger PA, Modzelewski RA, Shurin ZR, Rueger RM, Trump DL and Johnson CS: 1,25-Dihydroxycholecalciferol (1,25-D3) inhibits the growth of squamous cell carcinoma and down-modulates p21(Waf1/Cip1) in vitro and in vivo. Cancer Res 59: 2644-2649, 1999.

10. Bises G, Kállay E, Weiland T, Wrba F, Wenzl E, Bonner E, Kriwanek S, Obrist $\mathrm{P}$ and Cross HS: 25-hydroxyvitamin D3-1alpha-hydroxylase expression in normal and malignant human colon. J Histochem Cytochem 52: 985-989, 2004.
11. TrumpDL,Potter DM, Muindi J, Brufsky A and Johnson CS: Phase II trial of high-dose, intermittent calcitriol (1,25 dihydroxy vitamin D3) and dexamethasone in androgen-independent prostate cancer. Cancer 106: 2136-2142, 2006.

12. Bennett RG, Wakeley SE, Hamel FG, High RR, Korch C and Goldner WS: Gene expression of vitamin D metabolic enzymes at baseline and in response to vitamin $\mathrm{D}$ treatment in thyroid cancer cell lines. Oncology 83: 264-272, 2012.

13. Stepien T, Krupinski R, Sopinski J, Kuzdak K, Komorowski J, Lawnicka $\mathrm{H}$ and Stepien H: Decreased 1-25 dihydroxyvitamin D3 concentration in peripheral blood serum of patients with thyroid cancer. Arch Med Res 41: 190-194, 2010.

14. Peehl DM and Feldman D: Interaction of nuclear receptor ligands with the Vitamin D signaling pathway in prostate cancer. J Steroid Biochem Mol Biol 92: 307-315, 2004.

15. Ma Y, Trump DL and Johnson CS: Vitamin D in combination cancer treatment. J Cancer 1: 101-107, 2010.

16. Evans TR, Colston KW, Lofts FJ, Cunningham D, Anthoney DA, Gogas H, de Bono JS, Hamberg KJ, Skov T and Mansi JL: A phase II trial of the vitamin D analogue Seocalcitol (EB1089) in patients with inoperable pancreatic cancer. Br J Cancer 86: 680-685, 2002.

17. Dalhoff K, Dancey J, Astrup L, Skovsgaard T, Hamberg KJ, Lofts FJ, Rosmorduc O, Erlinger S, Hansen JB, Steward WP, et al: A phase II study of the vitamin D analogue Seocalcitol in patients with inoperable hepatocellular carcinoma. Br J Cancer 89: 252-257, 2003 .

18. Mikhail N: Clinical significance of vitamin D deficiency in primary hyperparathyroidism, and safety of vitamin D therapy. South Med J 104: 29-33, 2011.

19. Cho YL, Christensen C, Saunders DE, Lawrence WD, Deppe G, Malviya VK and Malone JM: Combined effects of 1,25-dihydroxyvitamin D3 and platinum drugs on the growth of MCF-7 cells. Cancer Res 51: 2848-2853, 1991

20. Liu G, Hu X and Chakrabarty S: Vitamin D mediates its action in human colon carcinoma cells in a calcium-sensing receptor-dependent manner: Downregulates malignant cell behavior and the expression of thymidylate synthase and survivin and promotes cellular sensitivity to 5-FU. Int J Cancer 126: 631-639, 2010.

21. Tanaka H, Abe E, Miyaura C, Kuribayashi T, Konno K, Nishii Y and Suda T: 1 alpha,25-Dihydroxycholecalciferol and a human myeloid leukaemia cell line (HL-60). Biochem J 204: 713-719, 1982.

22. Lechner D, Kállay E and Cross HS: 1alpha,25-dihydroxyvitamin D3 downregulates CYP27B1 and induces CYP24A1 in colon cells. Mol Cell Endocrinol 263: 55-64, 2007.

23. Jones G, Prosser DE and Kaufmann M: Cytochrome P450-mediated metabolism of vitamin D. J Lipid Res 55: 13-31, 2014.

24. Barry EL, Rees JR, Peacock JL, Mott LA, Amos CI, Bostick RM, Figueiredo JC, Ahnen DJ, Bresalier RS, Burke CA and Baron JA: Genetic variants in CYP2R1, CYP24A1, and VDR modify the efficacy of vitamin D3 supplementation for increasing serum 25-hydroxyvitamin D levels in a randomized controlled trial. J Clin Endocrinol Metab 99: E2133-E2137, 2014.

25. Bareis P, Kállay E, Bischof MG, Bises G, Hofer H, Pötzi C, Manhardt T, Bland R and Cross HS: Clonal differences in expression of 25-hydroxyvitamin $\mathrm{D}(3)$-1alpha-hydroxylase, of 25-hydroxyvitamin D(3)-24-hydroxylase, and of the vitamin D receptor in human colon carcinoma cells: Effects of epidermal growth factor and 1alpha,25-dihydroxyvitamin D(3). Exp Cell Res 276: 320-327, 2002.

26. Leevers SJ, Vanhaesebroeck B and Waterfield MD: Signalling through phosphoinositide 3-kinases: The lipids take centre stage. Curr Opin Cell Biol 11: 219-225, 1999.

27. Vivanco I and Sawyers CL: The phosphatidylinositol 3-Kinase AKT pathway in human cancer. Nat Rev Cancer 2: 489-501, 2002.

28. Fresno Vara JA, Casado E, de Castro J, Cejas P, Belda-Iniesta C and González-Barón M: PI3K/Akt signalling pathway and cancer. Cancer Treat Rev 30: 193-204, 2004.

29. Mandal M, Kim S, Younes MN, Jasser SA, El-Naggar AK, Mills GB and Myers JN: The Akt inhibitor KP372-1 suppresses Akt activity and cell proliferation and induces apoptosis in thyroid cancer cells. Br J Cancer 92: 1899-1905, 2005.

30. Hou P, Liu D, Shan Y, Hu S, Studeman K, Condouris S, Wang Y, Trink A, El-Naggar AK, Tallini G, et al: Genetic alterations and their relationship in the phosphatidylinositol 3-kinase/Akt pathway in thyroid cancer. Clin Cancer Res 13: 1161-1170, 2007. 
31. Abbosh PH and Nephew KP: Multiple signaling pathways converge on beta-catenin in thyroid cancer. Thyroid 15: 551-561, 2005.

32. Rubinfeld B, Albert I, Porfiri E, Munemitsu S and Polakis P: Loss of beta-catenin regulation by the APC tumor suppressor protein correlates with loss of structure due to common somatic mutations of the gene. Cancer Res 57: 4624-4630, 1997.

33. Morin PJ, Sparks AB, Korinek V, Barker N, Clevers H, Vogelstein B and Kinzler KW: Activation of beta-catenin-Tcf signaling in colon cancer by mutations in beta-catenin or APC. Science 275: 1787-1790, 1997.

34. Korinek V, Barker N, Morin PJ, van Wichen D, de Weger R, Kinzler KW, Vogelstein B and Clevers H: Constitutive transcriptional activation by a beta-catenin-Tcf complex in APC-/- colon carcinoma. Science 275: 1784-1787, 1997.

35. Garcia-Rostan G, Camp RL, Herrero A, Carcangiu ML, Rimm DL and Tallini G: Beta-catenin dysregulation in thyroid neoplasms: Down-regulation, aberrant nuclear expression, and CTNNB1 exon 3 mutations are markers for aggressive tumor phenotypes and poor prognosis. Am J Pathol 158: 987-996, 2001

36. Kramer C, Seltmann H, Seifert M, Tilgen W, Zouboulis CC and Reichrath J: Characterization of the vitamin D endocrine system in human sebocytes in vitro. J Steroid Biochem Mol Biol 113: 9-16, 2009.

37. Tokar EJ and Webber MM: Cholecalciferol (vitamin D3) inhibits growth and invasion by up-regulating nuclear receptors and 25-hydroxylase (CYP27A1) in human prostate cancer cells. Clin Exp Metastasis 22: 275-284, 2005.

38. Livak KJ and Schmittgen TD: Analysis of relative gene expression data using real-time quantitative PCR and the 2(-Delta Delta C(T)) method. Methods 25: 402-408, 2001.

39. Ordoñez-Morán P and Muñoz A: Nuclear receptors: Genomic and non-genomic effects converge. Cell Cycle 8: 1675-1680, 2009.

40. Kósa JP, Horváth P, Wölfling J, Kovács D, Balla B, Mátyus P, Horváth E, Speer G, Takács I, Nagy Z, et al: CYP24A1 inhibition facilitates the anti-tumor effect of vitamin D3 on colorectal cancer cells. World J Gastroenterol 19: 2621-2628, 2013.

41. Nieto MA: Epithelial plasticity: A common theme in embryonic and cancer cells. Science 342: 1234850, 2013.

42. Tam WL and Weinberg RA: The epigenetics of epithelialmesenchymal plasticity in cancer. Nat Med 19: 1438-1449, 2013.

43. Liu F, Gu LN, Shan BE, Geng CZ and Sang MX: Biomarkers for EMT and MET in breast cancer: An update. Oncol Lett 12: 4869-4876, 2016.
44. Yoo YA, Kang MH, Lee HJ, Kim BH, Park JK, Kim HK, Kim JS and Oh SC: Sonic hedgehog pathway promotes metastasis and lymphangiogenesis via activation of Akt, EMT, and MMP-9 pathway in gastric cancer. Cancer Res 71: 7061-7070, 2011.

45. Kawamata H, Kawai K, Kameyama S, Johnson MD, Stetler-Stevenson WG and Oyasu R: Over-expression of tissue inhibitor of matrix metalloproteinases (TIMP1 and TIMP2) suppresses extravasation of pulmonary metastasis of a rat bladder carcinoma. Int J Cancer 63: 680-687, 1995.

46. Baryawno N, Sveinbjörnsson B, Eksborg S, Chen CS, Kogner P and Johnsen JI: Small-molecule inhibitors of phosphatidylinositol 3-kinase/Akt signaling inhibit Wnt/beta-catenin pathway cross-talk and suppress medulloblastoma growth. Cancer Res 70: 266-276, 2010.

47. Tashiro K, Abe T, Oue N, Yasui W and Ryoji M: Characterization of vitamin D-mediated induction of the CYP 24 transcription. Mol Cell Endocrinol 226: 27-32, 2004.

48. Bates RC and Mercurio AM: The epithelial-mesenchymal transition (EMT) and colorectal cancer progression. Cancer Biol Ther 4: 365-370, 2005.

49. Liu Y, Sun X, Feng J, Deng LL, Liu Y, Li B, Zhu M, Lu C and Zhou L: MT2-MMP induces proteolysis and leads to EMT in carcinomas. Oncotarget 7: 48193-48205, 2016.

50. Li J and Zhou BP: Activation of $\beta$-catenin and Akt pathways by Twist are critical for the maintenance of EMT associated cancer stem cell-like characters. BMC Cancer 11: 49, 2011.

51. Sastre-Perona A, Riesco-Eizaguirre G, Zaballos MA and Santisteban P: $\beta$-catenin signaling is required for RAS-driven thyroid cancer through PI3K activation. Oncotarget 7: 49435-49449, 2016.

52. Lee G, Goretsky T, Managlia E, Dirisina R, Singh AP, Brown JB, May R, Yang GY, Ragheb JW, Evers BM, et al: Phosphoinositide 3-kinase signaling mediates beta-catenin activation in intestinal epithelial stem and progenitor cells in colitis. Gastroenterology 139: 869-881.e1-e9, 2010

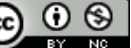

This work is licensed under a Creative Commons Attribution 4.0 International (CC BY-NC 4.0) License 